\title{
The Role of Helicobacter pylori Outer Membrane Proteins in Adherence and Pathogenesis
}

\author{
Mónica Oleastro ${ }^{1}$ and Armelle Ménard ${ }^{2,3, *}$
}

1 Department of Infectious Diseases, National Institute of Health Dr Ricardo Jorge, 1649-016 Lisbon, Portugal; E-Mail: monica.oleastro@insa.min-saude.pt

2 INSERM U853, Infection à Helicobacter, inflammation et cancer, Bordeaux 33076, France

3 Laboratoire de Bactériologie, Université de Bordeaux, Bordeaux 33076, France

* Author to whom correspondence should be addressed; E-Mail: armelle.menard@u-bordeaux2.fr; Tel.: +33-5-5757-1288; Fax: +33-5-5651-4182.

Received: 4 June 2013; in revised form: 26 July 2013 / Accepted: 13 August 2013 /

Published: 27 August 2013

\begin{abstract}
Helicobacter pylori is one of the most successful human pathogens, which colonizes the mucus layer of the gastric epithelium of more than $50 \%$ of the world's population. This curved, microaerophilic, Gram-negative bacterium induces a chronic active gastritis, often asymptomatic, in all infected individuals. In some cases, this gastritis evolves to more severe diseases such as peptic ulcer disease, gastric adenocarcinoma, and gastric mucosa-associated lymphoid tissue lymphoma. H. pylori has developed a unique set of factors, actively supporting its successful survival and persistence in its natural hostile ecological niche, the human stomach, throughout the individual's life, unless treated. In the human stomach, the vast majority of $H$. pylori cells are motile in the mucus layer lining, but a small percentage adheres to the epithelial cell surfaces. Adherence to the gastric epithelium is important for the ability of $H$. pylori to cause disease because this intimate attachment facilitates: (1) colonization and persistence, by preventing the bacteria from being eliminated from the stomach, by mucus turnover and gastric peristalsis; (2) evasion from the human immune system and (3) efficient delivery of proteins into the gastric cell, such as the CagA oncoprotein. Therefore, bacteria with better adherence properties colonize the host at higher densities. H. pylori is one of the most genetically diverse bacterial species known and is equipped with an extraordinarily large set of outer membrane proteins, whose role in the infection and persistence process will be discussed in
\end{abstract}


this review, as well as the different receptor structures that have been so far described for mucosal adherence.

Keywords: bacterial adherence; adhesin; receptor; virulence; gastric disease; outer membrane protein; Lewis antigen

\section{Introduction: Helicobacter pylori-A Successful Pathogen}

About 30 years ago, Barry Marshall and Robin Warren reported the isolation and culture of a spiral bacterial species from the human stomach [1]. Helicobacter pylori previously named Campylobacter pyloridis is a curved microaerophilic Gram-negative bacterium, 2 to $4 \mu \mathrm{m}$ long with a diameter of 0.5 to $1 \mu \mathrm{m}$. This spiral-shaped bacillus is highly motile due to its unipolar bundle of two to six sheathed flagella and it colonizes the mucus layer of the gastric epithelium of humans. The bacterium migrated out of Africa along with our ancestors and has been intertwined with our species for at least two hundred thousand years [2]. While not as deadly as some bacteria, H. pylori is the most successful pathogen in human history since it infects up to half of the world's population. The prevalence of H. pylori infection is the highest in developing countries (up to $100 \%$ ) where risk factors are mainly low socioeconomic conditions including large family size, while decreasing in Western countries $(10 \%-60 \%)$. The most common routes of $H$. pylori transmission are oral-to-oral and fecal-to-oral contact. Parents and siblings seem to play a major role in transmission.

Acquisition of $H$. pylori infection occurs predominantly in childhood, with more severe gastroduodenal diseases appearing mostly during adulthood. Although $H$. pylori infection always causes a chronic active gastritis, the majority of infected individuals ( $\sim 85 \%)$ remain asymptomatic throughout life. In some cases, this gastric inflammation may evolve toward more severe diseases such as duodenal or gastric ulcers, gastric mucosa-associated lymphoid tissue (MALT) lymphoma or non-cardia gastric adenocarcinoma. H. pylori infection was classified as a type I carcinogen in 1994 by the International Agency for Research on Cancer (World Health Organization) [3]. Indeed, H. pylori infection is the main risk factor in up to $92 \%$ of gastric cancers [4] and this cancer is the fourth most common and second most deadly cancer worldwide, with approximately 740,000 deaths per year. Studies have also associated $H$. pylori infection with diverse extragastric nonmalignant diseases [5].

In the absence of an effective vaccine, antibiotic treatment cures peptic ulcer disease and gastric MALT lymphoma permanently (when the treatment is given before the MALT lymphoma becomes autonomous) while gastric adenocarcinoma is difficult to prevent unless it is found at an early stage [6]. H. pylori infection can be difficult to treat and requires the combined intake of a proton pump inhibitor with amoxicillin and one of two antibiotics, clarithromycin or metronidazole [7]. More virulent $H$. pylori isolates harbour numerous well-known adhesins $(\mathrm{BabA} / \mathrm{B}, \mathrm{SabA}, \mathrm{AlpA} / \mathrm{B}$, OipA and HopZ), the vacuolating cytotoxin VacA and the oncoprotein CagA. The cagA gene belongs to the $\operatorname{cag}$ pathogenicity island (PAI), which encodes a type IV secretion system (T4SS), a needle-like pilus device that delivers effector proteins such as the CagA oncoprotein into the cytoplasm of gastric epithelial cells (for review see [8] and references cited therein). 
The adherence of $H$. pylori to the mucus layer of the gastric epithelium plays an important role in the initial colonization and persistence of the bacteria in the human stomach during decades or for an entire lifetime. H. pylori colonization of the stomach elicits humoral and cellular immune responses which in most cases do not result in bacterial clearance. The bacterium has developed a unique set of factors, actively supporting its successful survival and persistence in its natural hostile ecological niche, the human stomach, throughout the individual's life, unless treated. The bacterium is one of the most diverse and variable bacterial species known, constituting a valuable advantage to evade the host immune system. Almost every isolate from unrelated patients appears to have a unique "fingerprint". Moreover, individuals can be colonized with multiple strains, and strains have been shown to evolve during chronic colonization. Not only does almost every infected person carry his/her own individual $H$. pylori strain, but strains can undergo genetic alteration in vivo, driven by an elevated mutation rate and an extensive exchange of genetic material $[9,10]$, leading to free recombination of $H$. pylori genes. These phenomena result in the plasticity of the expression profile of $H$. pylori, also affecting surface proteins such as the outer membrane proteins (OMPs) [11], and suggest that H. pylori rapidly adapts to individual hosts; for review see [12] and references cited therein. In fact, it was recently demonstrated that short-term mutation rates in $H$. pylori could be quite fast, partially overlapping with those of viruses [13], with each strain of these hypermutable bacteria acting as a quasispecies [14]. The genetic variability of $H$. pylori affects housekeeping genes, virulence genes, lipopolysaccharide (LPS) and numerous OMP encoding genes, thus contributing to host adaptation, persistence and immune response evasion, giving rise to chronic inflammatory reactions. This review presents the recent progress in characterizing the role of the various Lewis-like antigens and adhesins in the interaction with host cell factors. The role of these interactions in bacterial colonization and pathogenesis is discussed.

\section{Helicobacter pylori Adherence-Associated Molecules}

\subsection{Lipopolysaccharide (LPS)}

LPS is the major component of the bacterial cell wall of Gram-negative bacteria. It is an organic compound found in the outer leaflet of outer membranes which contributes to the structural integrity of the bacteria and protects the membrane. Similar to other Gram-negative bacteria, the LPS of H. pylori is essential for the bacteria's survival. The LPS of $H$. pylori consists of an O-specific polysaccharide chain, a core oligosaccharide, and a lipid part called lipid A, embedded in the outer membrane. While LPS is often highly toxic for the host, that of H. pylori is low in activation of the host immunological responses [15].

The O-antigen of $H$. pylori LPS contains different human Lewis-like antigens, including Lewis $(\mathrm{Le})^{\mathrm{x}}, \mathrm{Le}^{\mathrm{y}}, \mathrm{Le}^{\mathrm{a}}$ and $\mathrm{Le}^{\mathrm{b}}$, which are also expressed in gastric epithelial cells [16]. It was hypothesized that these $H$. pylori LPS Lewis-like antigens could play a role in adherence to gastric epithelial cells in $\mathrm{a}$ in a Lewis-antigen-dependent manner, more specifically via $\mathrm{Le}^{\mathrm{x}}$. Moreover, since they undergo phase variation and antigenic variation within a single strain, this would provide the bacteria with a dynamic adherent phenotype [17-19]. Several studies support the role of LPS as an adherence factor of H. pylori. In one study, a monoclonal antibody that inhibited H. pylori adherence to gastric epithelial cells by up to $75 \%$ was shown to target the LPS possibly through the O-antigen Le ${ }^{\mathrm{x}}$ portion [20]. More 
recently, the receptor recognized by the O-antigen side-chain of $H$. pylori LPS was identified as being a host $\beta$-galactoside-binding lectin, galectin-3 [21]. This study also showed that expression of galectin-3 is up regulated by gastric epithelial cells following adherence of $H$. pylori, suggesting that, in addition to colonization, this lectin also plays a role in the host response to infection.

Data from other studies indicate however that Lewis-like antigens seem to only have a limited role in bacterial adherence, which is most likely overcome by the strong adherence phenotype mediated by H. pylori adhesins [22,23].

\subsection{Outer Membrane Proteins}

The OMP profile of $H$. pylori strains differs significantly from that of other Gram-negative species as no major OMPs predominate, rather multiple lower-abundance OMPs are observed [24]. Approximately $4 \%$ of the $H$. pylori genome encodes an extraordinary large set of OMPs ( 64 OMPs) divided into five paralogous gene families [24] (Figure 1) and this unusual set of OMPs may be a reflection of the adaptation of $H$. pylori to the unique gastric environment where it is found. The largest family is Family 1, comprised of the Hop (for H. pylori OMP, 21 members) and Hor (for Hop related, 12 members) proteins. Families 2 and 3 comprise the Hof (for Helicobacter OMP, 8 members) and Hom (for Helicobacter outer membrane, 4 members) proteins, respectively. Families 4 and 5 are composed of iron-regulated OMPs (6 members) and efflux pump OMPs (3 members), respectively. Other OMPs ( $\sim 10$ members) were not included in these families [24].

Members of the Hop family share highly similar or identical sequences at their amino and carboxyl termini and include porins $[25,26]$ and several known or predicted H. pylori adhesins which promote binding to the gastric epithelium [27,28]. In addition, another OMP from the third family, HomB, was shown to be involved in $H$. pylori adherence [29].

The level of the expression of H. pylori OMPs can be altered and regulated by several mechanisms, of which the most important are: gene conversion and gene duplication, regulation by phase variation and allelic variation. Several examples of these mechanisms are described in the paragraphs below.

\subsubsection{BabA}

The major H. pylori adhesin is the blood group antigen-binding adhesin A, named BabA or HopS or OMP28 $(\sim 80 \mathrm{kDa})$, which was the first identified adhesin in $H$. pylori; for review see [30,31] and references cited therein. BabA, mediates the binding of the bacterium to the fucosylated Lewis b blood group antigen, $\mathrm{Le}^{\mathrm{b}}[27,32]$ and related terminal fucose residues found on blood group $\mathrm{O}$ ( $\mathrm{H}$ antigen), A and B antigens [33] which are expressed on the surface of mucins (MUC1 and MUC5B) and gastric epithelial cells, $\mathrm{Le}^{\mathrm{b}}$ being the dominant antigen in the gastric mucosa [34]. BabA binds to blood group determinants on both type 1 and type 4 core chains [35]. BabA adhesin also binds to the salivary mucin MUC5B, a proline-rich glycoprotein, and to the non-mucin glycoprotein gp-340 [36,37] (Table 1). 
Figure 1. Phylogenetic analysis of the large the set of outer membrane proteins identified in Helicobacter pylori.

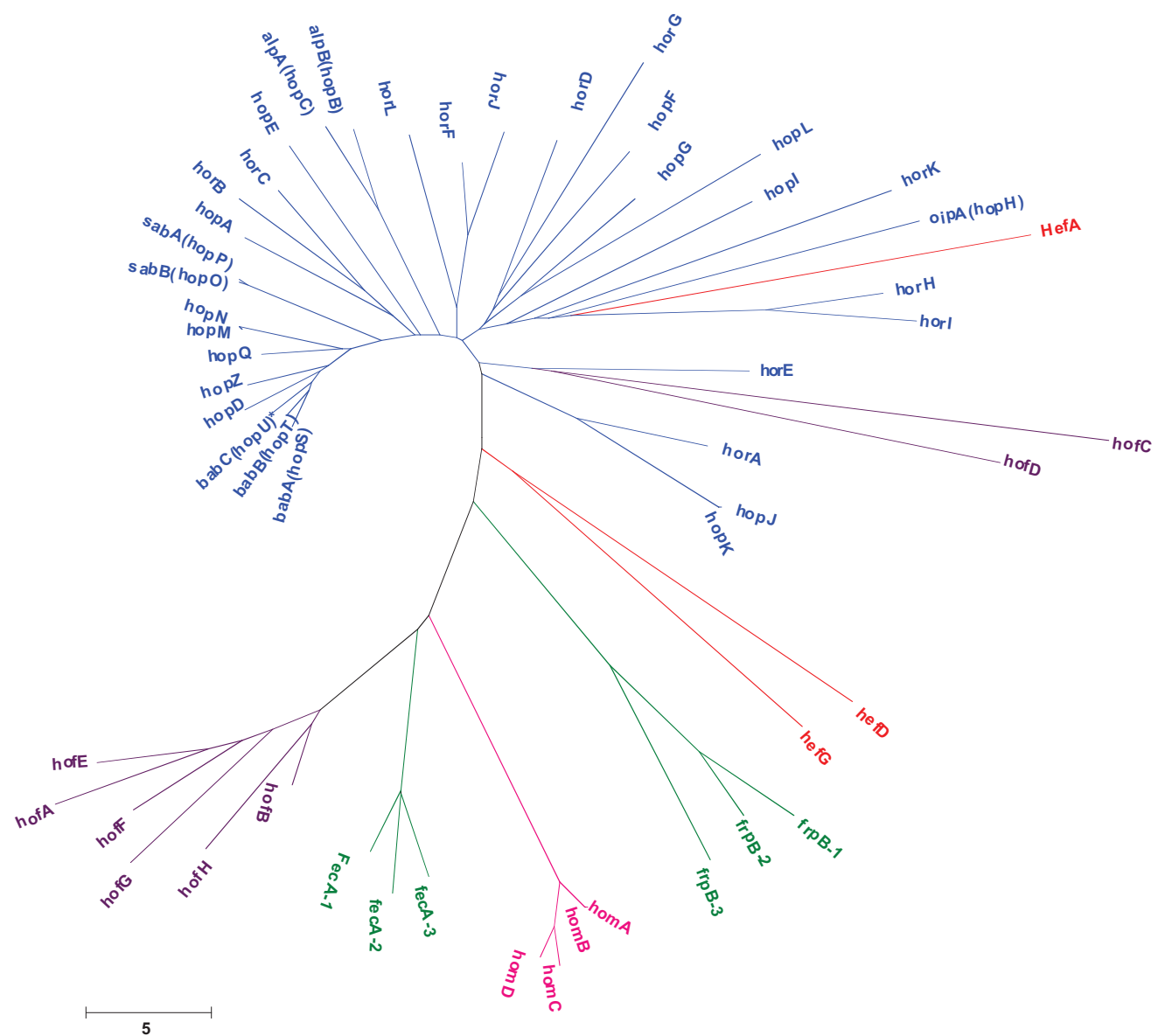

The five major families of outer membrane proteins (OMP) previously reported [24] are represented. The OMP gene sequences provided from the H. pylori strain J99 [24], except for the babC gene (absent in the J99 strain) provided from the 26695 strain. Family 1 (blue) comprises 21 members named Hop (21 members) and Hor $(12$ members) proteins. Families 2 (red) and 3 (pink) comprise the Hof $(8$ members) and Hom (4 members) proteins, respectively. Families 4 (green) and 5 (red) are composed of iron-regulated OMPs (6 members) and efflux pump OMPs ( 3 members), respectively. The 10 other non-classified OMPs are not included in the phylogenetic tree [24]. The duplicated Hop proteins $(\mathrm{HopJ} / \mathrm{K}$ and $\mathrm{HopM} / \mathrm{N})$ were not differentiated and are each visualized as one line. Neighbour-joining phylogenetic tree topologies of H. pylori OMP genes were constructed using the MEGA (Molecular Evolutionary Genetics Analysis) 5.1 software [38], on the basis of distances estimated using the Maximum Composite Likelihood model [39]. Branching significance was estimated using bootstrap confidence levels by randomly resampling the data 1,000 times with the referred evolutionary distance model. The branch length index is represented below the tree. ${ }^{*} b a b \mathrm{C}$ gene sequence provided from the H. pylori 26695 strain. Hop, Helicobacter pylori OMP; Hor, Hop related; Hof, Helicobacter OMP, Hom, Helicobacter outer membrane.

Table 1. Helicobacter pylori adhesins and their receptors.

\begin{tabular}{clc}
\hline Adhesins & Receptors identified & References \\
\hline BabA & fucosylated Lewis b histo-blood group antigen, Leb and H1 & {$[27,32]$} \\
BabA & terminal fucose residues on blood group O (H antigen), A and & {$[33]$} \\
& B antigens & {$[37]$} \\
BabA & salivary nonmucin glycoprotein gp-340 & {$[36,37]$} \\
BabA & salivary mucin MUC5B * and proline-rich glycoprotein & \\
\hline
\end{tabular}


Table 1. Cont.

\begin{tabular}{clc}
\hline Adhesins & Receptors identified & References \\
\hline SabA & sialyl-dimeric-Lex & {$[28]$} \\
SabA & salivary mucin MUC7, MUC5B * & {$[36,37]$} \\
& salivary glycoproteins (carbonic anhydrase VI, secretory & \\
SabA & component, heavy chain of secretory IgA1, parotid secretory & {$[37]$} \\
& protein and zinc- $\alpha 2-$ glycoprotein) & \\
SabA & sialylated moieties on the extracellular matrix protein laminin & {$[36]$} \\
SabA & sialylated structures on the surface of erythrocytes & {$[40]$} \\
SabA & sialylated carbohydrates on neutrophils & {$[41]$} \\
AlpA & laminin & {$[42,43]$} \\
AlpB & laminin & {$[42,43]$} \\
\hline
\end{tabular}

An additional unidentified bacterial surface component (different from BabA and SabA) also mediates the binding to unknown receptor moieties of fibronectin and lactoferrin [36]; * MUC5B carries both fucosylated blood group antigens and $\alpha 2-3$-linked sialic acids.

BabA adhesin has closely related paralogs (Figure 1), BabB (HopT or OMP19) and BabC (HopU or OMP9), whose function have not yet been determined. All of these genes present extensive 5' and 3' homology, in particular babA and babB [44], suggesting that the middle variable region of BabA most likely encodes the specific adhesin function. Five different allele groups of babA (AD1 to AD5) and three different allele groups of $b a b \mathrm{~B}$ (BD1 to $\mathrm{BD} 3$ ) were observed within this variable region, none of these alleles being a determining factor in $\mathrm{Le}^{\mathrm{b}}$ binding of $H$. pylori strains [45]. Phylogenetic analysis revealed that the allelic groupings of $b a b \mathrm{~A}$ and $b a b \mathrm{~B}$ are independent of one another and that, for both, geographic variation is present [45]. Although babA/babB 5' and middle regions showed strong interstrain similarity, the $3^{\prime}$ segments revealed strong intrastrain similarity, indicative of concerted evolution. This segment also demonstrates geographic clustering among H. pylori strains [44]. BabA expression is regulated both at transcriptional and translational levels [44,46-51]. babA, babB and $b a b \mathrm{C}$ paralogs can be present at multiple loci, with $b a b \mathrm{~A}$ and $b a b \mathrm{~B}$ usually present at loci $\mathrm{A}$ and $\mathrm{B}$, respectively, while the locus $C$ is rarely occupied [46,52,53]. Gene conversion (see Section 3 below) frequently occurs between the loci $\mathrm{A}$ and $\mathrm{B}$, most likely by RecA-dependent intragenomic recombination between complementary loci [44] leading to chimeric $b a b \mathrm{~B} / \mathrm{A}$ and $b a b \mathrm{~A} / \mathrm{B}$ genes [46-49]. For example, non $\mathrm{Le}^{\mathrm{b}}$ binding strains can regain $\mathrm{Le}^{\mathrm{b}}$ binding activity by recombination into the $b a b \mathrm{~B}$ locus leading to the $\mathrm{BabB} / \mathrm{A}$ chimera able to bind $\mathrm{Le}^{\mathrm{b}}$ [47]. In vivo loss of $\mathrm{BabA}$ expression and $\mathrm{Le}^{\mathrm{b}}$ binding was also reported in animal models [48,50,51]. The loss of BabA adherence is due to (1) the modification of six amino acid residues critical for the binding to fucosylated blood group antigens [50], (2) nucleotide(s) substitution, deletion (up tp $84 \mathrm{bp}$ ) or insertion (1 bp) within various portions of the babA gene resulting in a truncated BabA translation product [51] or (3) phase variation through a slipped strand mechanism (SSM) based on the number of Cysteine-Threonine (CT) dinucleotide repeats in the $5^{\prime}$ region of the gene $[27,46,48,50]$. These CT repeats are probably the result of chromosomal translocation events. Initially, two babA "alleles" were reported; babA2 allele is expressed and involved in the $\mathrm{Le}^{\mathrm{b}}$ binding activity, while the rarest babAl is not expressed due to a $10 \mathrm{bp}$ deletion in its signal peptide sequence [27] that eliminates its translational initiation codon and 
also due to the presence of four additional nucleotides between the 10- and 35-sites of the babA1 promoter, diminishing the strength of the promoter [47].

Both in vitro and in vivo experiments revealed that BabA-mediated adherence to $\mathrm{Le}^{\mathrm{b}}$ on the epithelial surface is a potentiator of the $H$. pylori T4SS secretion system activity, thus triggering the transcription of genes which enhance inflammation, development of intestinal metaplasia, and associated precancerous transformations [54]. BabA binding to $\mathrm{Le}^{\mathrm{b}}$ is also important for the induction of DNA double-strand breaks and a DNA damage response in host cells in a manner independent of VacA, $\gamma$-glutamyl transpeptidase and the cag PAI [55].

The presence of babA is associated with cagA and vacA toxigenic s1 alleles. However, most PCR-based methods currently used to determine the babA status do not evaluate the babA transcriptional regulation mechanisms (see above) that could result in loss of BabA adherence [56]. A few studies evaluated the BabA status by immunoenzymatic-based methods and $\mathrm{Le}^{\mathrm{b}}$ binding activity. They nevertheless confirmed that the BabA-positive status of infecting strains is associated with CagA and VacAs1 and the presence of intestinal metaplasia and degenerative alterations in human biopsies [57]. BabA-positive status is also closely associated with severe clinical outcomes [58]. Surprisingly, a small group of strains producing low levels of BabA and lacking $\mathrm{Le}^{\mathrm{b}}$ binding activity were more likely to be associated with increased mucosal inflammation and severe clinical outcomes than BabA-positive strains with $\mathrm{Le}^{\mathrm{b}}$ binding activity [56]. The underlying mechanism remains unclear and further studies are necessary to investigate the functional coordination of the BabA-receptor network during interaction of $H$. pylori with the gastric epithelium [30].

\subsubsection{SabA}

The sialic acid-binding adhesin, SabA or HopP or OMP17 $(\sim 70 \mathrm{KDa})$, is the second most well characterized adhesin of $H$. pylori; for review see [59] and references cited therein. Upon H. pylori infection and the resulting mucosal inflammation, the sialyl-dimeric-Lewis $\mathrm{x}\left(\mathrm{Le}^{\mathrm{x}}\right)$ glycosphingolipid is upregulated and SabA mediates the binding of the bacterium to the sialyl-dimeric-Le ${ }^{\mathrm{x}}$ [28]. SabA adhesin also participates with BabA in the binding of $H$. pylori to a salivary mucin MUC5B, but to a lesser extent [36,37] (Table 1).

SabA has a closely related paralog, SabB (HopO, OMP16) [24] (Figure 1). The 5' and 3' ends of the sabA gene share the highest nucleotide identity with two genes, sabB [24] and another OMP, hopQ (OMP27) [60], whose function has not yet been determined; both may also be involved in H. pylori adherence [61,62]. Variability in copy number and locus of $s a b \mathrm{~A}$ and its paralogs, $s a b \mathrm{~B}$ and $h o p \mathrm{Q}$, also occurs among clinical H. pylori isolates [60]. Gene conversion is a mechanism for H. pylori to regulate the amount of SabA on the bacterial surface and adherence to mouse gastric tissue. Gene conversion mainly results from intragenomic recombination and occurs in vitro at a similar rate at both the $s a b \mathrm{~A}$ and $s a b \mathrm{~B}$ loci but at a lower rate at the hopQ locus. The $\mathrm{pH}$ appears to be another regulation mechanism of sabA expression. Indeed, sabA mRNA and SabA expression levels are decreased under acidic conditions $[63,64]$.

The sabA gene is one of the most divergent genes in the H. pylori genome [65] and is also regulated at transcriptional level by several mechanisms. Indeed, dinucleotide CT repeats present in the 5 ' coding region of sabA regulate its expression by phase variation through SSM $[61,64]$ and the sabA promoter 
region modulates its transcriptional activity through a variable homopolymeric thymidine tract [66]. The frequent "on/off" switch of SabA expression suggests that SabA expression can rapidly respond to changing conditions in the stomach. Molecular-based methods currently used to analyze the CT repeats do not correlate with SabA production defined by immunoblot [59], probably because of the frequent "on/off" switches. SabA positive status was inversely related to the ability of the stomach to secrete acid, suggesting that its expression may be regulated by changes in acid secretion and/or in antigens expressed by the atrophic mucosa [64].

The interaction between SabA and its ligand enhances the colonization density of $H$. pylori in patients lacking gastric $\mathrm{Le}^{\mathrm{b}}$ [67]. Moreover, H. pylori modulates the expression of the SabA ligand, the sialyl-dimeric-Le ${ }^{\mathrm{x}}$, in human gastric cell lines via the induction of a specific glycosyltransferase, $\beta 3$ GlcNAc T5 ( $\beta 3 \mathrm{GnT5}$ ), involved in the biosynthesis of Lewis antigens, thereby strengthening the epithelial attachment necessary to achieve successful colonization [68].

SabA has also been identified as a haemagglutinin which binds to sialylated structures found on the surface of erythrocytes, and there is a good correlation among strains between sialic acid dependent haemagglutination and sialyl Le ${ }^{\mathrm{x}}$ binding [40]. A high level of polymorphism in sialyl binding properties, similar to that observed for BabA, was reported among clinical H. pylori isolates, which suggests that SabA adapts to its host depending on the mucosal sialylation pattern of the infected individual [40].

Arrays and proteomic studies revealed that SabA also mediates the binding of $H$. pylori to sialylated moieties on the extracellular matrix protein laminin [36] and to salivary glycoproteins, including MUC7, carbonic anhydrase VI, secretory component, heavy chain of secretory IgA1, parotid secretory protein and zinc- $\alpha 2$-glycoprotein [37]. SabA was also found to interact with BabA in complexes that could be potentially implicated in the development of malignant diseases [69].

SabA-positive status was associated with gastric cancer, intestinal metaplasia, and corpus atrophy in Western strains [61] but not in Asian strains [67], suggesting differences between SabA and clinical outcome. Upon H. pylori induced gastritis, neutrophils and monocytes infiltrate into the gastric mucosa. SabA of nonopsonized H. pylori strains specifically binds to neutrophils through sialylated carbohydrates. As a consequence, the stimulated neutrophils produce reactive oxygen species causing oxidative damage of the gastric epithelium, demonstrating that SabA is nevertheless a true virulence factor [41].

\subsubsection{AlpA, AlpB}

The adherence associated lipoproteins AlpA (HopC or OMP20, $\sim 56 \mathrm{kDa}$ ) and AlpB (HopB or OMP21, $\sim 57 \mathrm{kDa}$ ) are encoded by highly homologous adjacent genes, alpA and alp B [24,70]. Both lipoproteins were found interacting in a $H$. pylori membrane complex [69,71] and are involved in gastric colonization [72]. Indeed, the corresponding mutants did not infect the stomachs of guinea pigs and Mongolian gerbils [73,74] and poorly colonized the stomachs of C57BL/6 mice [75]. AlpA and AlpB are essential in the adherence of the bacterium to human gastric tissue in a different pattern than that observed for the BabA-mediated adherence, suggesting that a different receptor may be involved [42]. Both lipoproteins contribute to host laminin binding and influence gastric inflammation in gerbils; the expression of plasmid-borne alp $\mathrm{A}$ or alp $\mathrm{B}$ confers laminin-binding ability to 
Escherichia coli [43]. No other host binding partner or receptor has yet been identified. In contrast to many other OMPs that are produced at extremely variable rates, AlpA and AlpB proteins are strongly coproduced and seem to be expressed by all clinical isolates, supporting their essential function [11]. The protein expression level of AlpA is nevertheless upregulated in response to oxidative stress [76]. AlpA and AlpB induce gastric injury by modulating proinflammatory intracellular signalling cascades upon infection [75]. However, discrepant results regarding the inflammatory effect of the alp $\mathrm{AB}$ locus were obtained after infection of mice and gerbils $[43,75]$; the AlpA-AlpB induced interleukin- 8 (IL-8) secretion seems to be related to the isolate's geographic origin [75]. The fact that both these proteins seem to be constitutively expressed by all $H$. pylori isolates and are recognized specifically by sera from $H$. pylori-infected patients $[71,77]$ makes these proteins attractive targets for the vaccine design $[78,79]$.

\subsubsection{OipA}

The outer inflammatory protein A (OipA, HopH or OMP13 34 kDa) was initially identified as a surface protein which promotes in vitro IL-8 secretion in a T4SS-independent manner and heightens gastric inflammation in vivo [80,81]. OipA regulates IL-8 secretion through PI3K/Akt and this regulation is dependent on FoxO1/3a inactivation [82]. However, the role of OipA in inflammation is controversial. Indeed, hopH mutagenesis did not alter epithelial IL-8 secretion in vitro [83] or inflammation in Mongolian gerbils [84]. While the OipA host receptor remains unknown, predicted exposed amino acid sequences were determined in silico [85] and will be useful in finding its receptor(s). Indeed, there is no doubt that OipA is involved in bacterial adherence to gastric cells in vitro [83]. The hop $\mathrm{H}$ gene does not have highly similar paralogs and is quite distant from other hop genes (Figure 1). OipA expression is regulated by phase variation within a CT dinucleotide repeat motif located in the 5 ' region of the hopH gene [80,86]. OipA "on"-status is significantly associated with more severe gastric diseases (duodenal ulcer and gastric cancer), high H. pylori density, and severe neutrophil infiltration [53,64,84,87], probably because of its association with other virulence factors or increased bacterial adherence and colonization [83]. The strong link between the OipA "on"-status and cagA suggests that OipA may contribute to the fitness of cagA-positive strains in vivo [53,83]. OipA is involved in $H$. pylori-induced focal adhesion kinase activation and cytoskeletal reorganization of gastric epithelial cells in the early stages of H. pylori infection [88]. Isogenic oipA mutants significantly reduce the phosphorylation of paxillin, a focal adhesion associated adaptor protein involved in the regulation of $H$. pylori-mediated gastric epithelial cell motility, and also actin stress fiber formation [89]. Inactivation of oipA also results in a decreased level of nuclear $\beta$-catenin in vitro and a reduced incidence of cancer in gerbils [84], indicative of the importance of this OMP in the virulence of $H$. pylori. Vaccination trials based on oral therapeutic immunization using OipA-DNA-based vaccines conferred effective protection against $H$. pylori challenge in mice with a strong Th1/Th2 immune response, eliminating H. pylori colonization in the stomach $[90,91]$.

\subsubsection{HopZ}

The hopZ (ompl) gene encodes a $74 \mathrm{kDa}$-protein (681 residues) located on the surface of the bacteria [92]. Immunofluorescence revealed that the HopZ variable region (amino-acids 126 to 281) is 
exposed. HopZ involvement in adherence was demonstrated in vitro as a hopZ-knockout mutant strain showed significantly reduced binding capacity to the gastric epithelial AGS cell line, compared to the corresponding wild-type strain [61]. No receptor could be identified for this putative adhesin. In vivo the role of the HopZ protein in adherence and colonization is not clear. Indeed, lack of production of HopZ did not affect the ability of the bacteria to colonize the stomachs of guinea pigs [73], while genetic inactivation of hopZ reduced the ability of $H$. pylori to survive in the stomachs of gnotobiotic transgenic mice [93]. Two allelic variants (I and II) were reported for the hopZ gene [92] and recombination events occurred and led to the exchange of allele fragments [94]. Although hop $\mathrm{Q}$ (OMP27) is the closest to hopZ gene (Figure 1), no recombination event between these loci has been reported to date.

The expression of the hopZ gene is regulated by SSM within CT dinucleotide repeats of different length localized at the $5^{\prime}$ end of the coding region [92]. The HopZ switch status influenced both H. pylori density and its colonization ability in mice [61]. The hopZ "off" status frequently switches to "on" during human infection [95] and this status selected during early infection remains subsequently stable, suggesting a strong in vivo selection for this putative adhesin during early colonization [94]. The expression status of hopZ does not seem to correlate with the disease outcome, except for MALT lymphoma associated strains that appear to express a significantly smaller amount of the protein [95-97]. The hopZ "off" status was indeed associated with the development of MALT lymphoma [98].

\subsubsection{HomB}

The smallest family of OMP is the Hom family constituted of four members. The most studied gene is hom $\mathrm{B}$ encoding the HomB protein $(\sim 75 \mathrm{KDa})$ expressed in the H. pylori outer membrane [29]. hom $\mathrm{B}$ has a closely related paralog, hom A (Figure 1), sharing 90\% sequence identity, especially at the $5^{\prime}$ and $3^{\prime}$ ends with the differences between the two confined to the middle region of the respective open reading frames [24]. Allelic diversity was observed in the middle region of the genes, with six different alleles currently identified and expressed in vivo [99]. HomA/B variants likely occur via the accumulation of single nucleotide polymorphisms. No correlation between any allele and disease outcome was observed. For each gene, a dominant worldwide allele was detected (allele $A I I$ for hom A and allele $A I$ for $h o m \mathrm{~B}$ ), suggesting that $\operatorname{hom} \mathrm{A} / \operatorname{hom} \mathrm{B}$ allelic variants are independent of the geographical origin of the strain. It was shown by an in silico approach that the most prevalent $A I$ and $A I I$ alleles result from a homologous recombination between the rarest allelic variants of each gene, with a crossover point localized in the middle of the genes, containing the allelic region [100]. As for $b a b \mathrm{~A} / b a b \mathrm{~B}$, segment 3 ( $3^{\prime}$ end) of hom $\mathrm{A} /$ hom $\mathrm{B}$ is under concerted evolution, in contrast to segment 1 (5' end) which displays a divergent evolution [44,99]. hom $\mathrm{A} /$ hom $\mathrm{B}$ can also be present at multiple well conserved loci $[24,99,101]$ and, although diversity regarding the number of copy does exist, there is a clear geographical specificity, suggesting an involvement of these genes in host adaptation. Furthermore, hom $\mathrm{A}$ and hom $\mathrm{B}$ sequence analysis also suggests regulation by phase variation [99].

HomB is present in the membrane of H. pylori and is antigenic in humans [29]. Moreover, the protein is associated with IL-8 secretion in vitro and contributes to bacterial adherence, both of these functions being correlated with the number of hom $\mathrm{B}$ copies present in a strain [29] (Figure 2). In contrast to hom A, hom $\mathrm{B}$ is associated with the presence of cagA [29,102-104], as well as 
inflammation and atrophy in the corpus [103]. It clearly appears that hom $\mathrm{B}$ is a marker of more virulent $H$. pylori strains, which influences the severity of disease and contributes to more severe clinical outcomes. However, the exact involvement of HomB in the duodenal ulcer or gastric cancer outcome is not completely elucidated and is likely to be influenced by the geographical origin of the isolate $[105,106]$. Despite HomB's role in adherence, a host receptor remains to be determined and will be a major challenge for future research.

Figure 2. Involvement of the outer membrane protein HomB of Helicobacter pylori in interleukin 8 secretion and adherence to gastric epithelial AGS cells.
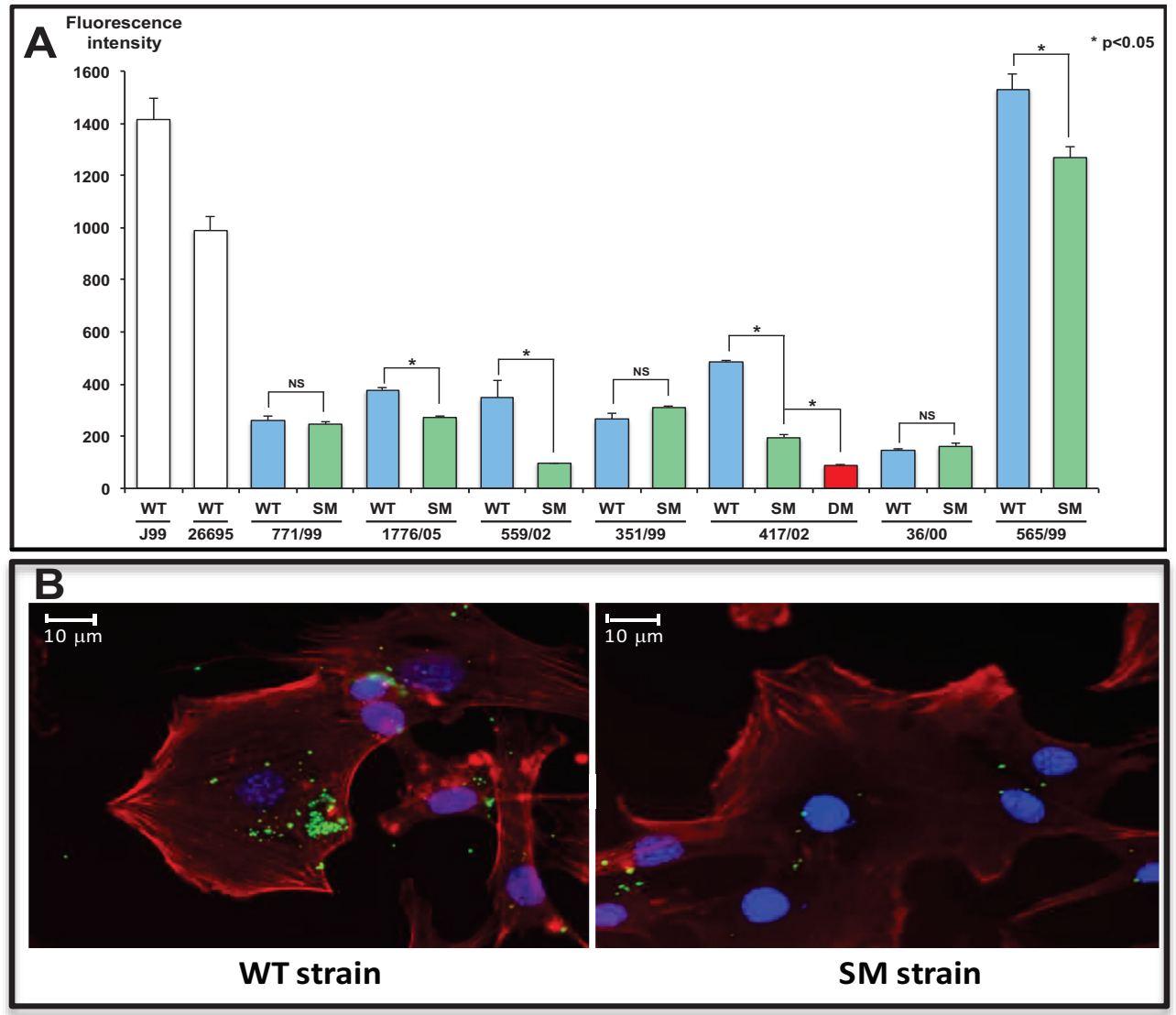

Cells were infected for $18 \mathrm{~h}$ with $\mathrm{H}$. pylori clinical strains, wild-type (WT) and homB knockout mutant strains, single mutant (SM) and double mutant (DM) strains, at a multiplicity of infection of 100. (A) Adherence of $H$. pylori was determined by flow cytometry after bacteria labelling using the $\mathrm{PKH} 2$ green fluorescent linker kit (Sigma). Values denote the means of the triplicate $( \pm \mathrm{SD})$. (Adapted from [29]). Two sequenced H. pylori strains 26695 (ATCC 700392) which were positive for hom A and negative for homB, and J99 (ATCC 700824) which was positive for both hom $\mathrm{A}$ and hom $\mathrm{B}$ were used as reference strains $[70,107]$. Seven $H$. pylori clinical strains were used. The latter strains were all homA negative. The strain 417/02 contained 2 copies of homB at the homA and homB locus (GenBank accession nos. EF648377 and EF648378, respectively). All of the other 6 strains carried a single copy of homB at the homB locus (strains 771/99, 1776/05, 559/02, 351/99, 36/00 and 565/99 (GenBank accession nos. EF648357, EF656577 to EF656579, EF648369 and EF648370). DM, double mutant; NS, not significant; SM, single mutant; WT, wild-type. (B) Adherence of $H$. pylori wild-type (WT) and single homB knockout mutant (SM) strains to AGS cells. AGS cells were processed for fluorescent staining with fluorescent labelled-phalloidin to detect F-actin (red) and Hoechst 33342 compound to detect the nucleus (blue). Primary antibody followed by fluorescent labelled-secondary antibodies (green) was used to detect $\mathrm{H}$. pylori. 


\section{Major Gastric Epithelial Receptors of $\boldsymbol{H}$. pylori}

H. pylori exhibits both host tropism, exclusively colonizing humans and some primates, and tissue tropism, adhering only to the gastric epithelial lining of the antrum or staying in the gastric mucus layer. In the duodenum, gastric metaplasia is a pre-requisite for the presence of the bacterium, and reports exist of H. pylori colonization at distant sites of gastric metaplasia, such as in Meckel's diverticula containing gastric mucosa and in the rectum $[108,109]$. In addition, $H$. pylori is not able to colonize areas of complete intestinal metaplasia in the gastric mucosa [110]. The majority of the bacteria remain in the mucus layer, with a smaller proportion colonizing the gastric surface.

\subsection{Lewis Blood Group Antigens}

H. pylori adheres to the mucus-secreting gastric epithelial cells of the lumen in the upper half of the gastric pit, but not to closely related mucus-secreting neck cells in the lower half of the gastric pit. H. pylori also does not adhere to chief cells, parietal cells, or endocrine cells in the gastric pit.

The major component of the gastric mucus layer are the highly glycosylated mucin proteins. In a healthy gastric mucosa, the human mucins (MUC) produced include MUC1, MUC5AC and MUC6. The membrane associated MUC1 is expressed in foveolar cells; the secreted MUC5AC mucin, a major constituent of the surface mucus gel layer, is restricted to the foveolar epithelium; and finally the expression of the secreted MUC6 is limited to the neck cells of the glands. This mucin distribution establishes the gastric glycosylation pattern as the expression of MUC5AC is accompanied by a similar distribution of fucosyltransferases, leading to co-expression of type 1 antigens, $\mathrm{Le}^{\mathrm{a}}$ and $\mathrm{Le}^{\mathrm{b}}$ and H-type 1 blood group antigens. Blood group antigens are a group of carbohydrates typically found on erythrocytes, and also highly expressed in epithelial tissues, including the gastric mucosa.

The fucosylated H-type 1 and $\mathrm{Le}^{\mathrm{b}}$ antigens are naturally expressed on the gastric mucosa of secretor or Lewis-positive individuals. The secretor status depends on an active $\alpha(1,2)$-fucosyltransferase that catalyses the addition of terminal $\alpha(1,2)$-fucose residues. On the other hand, MUC6 expression is associated with the type 2 antigens, $\mathrm{Le}^{\mathrm{x}}$ and $\mathrm{Le}^{\mathrm{y}}$, which are consequently located deeper in the glands, e.g., in the mucus, chief and parietal acid-producing cells [111,112].

Studies show that $H$. pylori is very closely associated with extracellular MUC5AC and epithelial cells that produce MUC5AC, indicating that MUC5AC, but not MUC6, plays a role in the adherence of $H$. pylori to the gastric mucosa [113]. In addition MUC6 exhibits an antimicrobial activity [114]. The major receptor for $H$. pylori is the $\mathrm{Le}^{\mathrm{b}}$ carbohydrate structure present in the normal gastric tissue and MUC5AC is the most important carrier of $\mathrm{Le}^{\mathrm{b}}$, with the attachment being made through BabA [115].

Several studies demonstrated that the glycosylation pattern of gastric mucins differs between individuals and changes during gastric disease evolution within an individual, implying that $H$. pylori has to constantly adapt to these environmental modifications. A recent study evaluated the effect of glycan expression modifications in $H$. pylori adherence, by using the animal model of non-secretors, Fut2-null mice, which exhibit a reduced expression of $\alpha(1,2)$ fucosylated structures on their gastric mucosa. It was shown that strains expressing a functional BabA adhesin showed decreased adherence to the gastric mucosa of the Fut2-null mice, while the binding pattern of strains expressing only the 
sialic acid-binding adhesin SabA was not altered, demonstrating that the impaired adherence could be attributed to reduced expression of BabA ligands in the gastric mucosa of Fut2-null mice [116].

\subsection{Sialylated Glycans}

All H. pylori-infected individuals develop a chronic gastritis, with extensive inflammation of the mucosa, with a small fraction developing pre-neoplastic alterations such as atrophic gastritis and in a later stage intestinal metaplasia [117]. Under these clinical conditions, $\mathrm{Le}^{\mathrm{b}}$ is weakly expressed while there is an upward migration of $\mathrm{Le}^{\mathrm{x}}$ associated with atrophy of the epithelium. Moreover, inflammation of the gastric mucosa leads to the expression of sialylated glycans, such as sialyl-Le ${ }^{\mathrm{a}}$ and sialyl-Le ${ }^{\mathrm{x}}$. In these cases, H. pylori will bind to sialyl-Le ${ }^{\mathrm{x}}$ via SabA adhesins [28]. Accordingly, it was demonstrated that SabA interaction with the host gastric sialyl-Le ${ }^{\mathrm{x}}$ antigen enhanced $H$. pylori colonization in patients with weak or no $\mathrm{Le}^{\mathrm{b}}$ expression [67].

\section{The Importance of Adherence for Bacterial Colonization and Virulence}

H. pylori is very well adapted to its host and persists for decades in the human stomach. During an established infection, some of the H. pylori cells attach themselves directly to epithelial cells, while the vast majority of the cells $(\sim 70 \%)$ are found in the mucus layer of the superficial gastric mucosa, either motile or adhering to the heavily glycosylated secreted mucins. This location favours the acquisition of nutrients released from the damaged host cells and delivery of effector molecules into the gastric cell, such as the CagA oncoprotein and the VacA cytotoxin, while at the same time bacteria are prevented from being eliminated from the stomach by mucus turnover and gastric peristalsis. However, the tight adherence of $H$. pylori to the mucosa may be deleterious when host inflammatory and immune responses are robust. Thus, the bacteria must be able to manage, in a fast and effective way, the delicate balance between the adherent and the motile population.

The importance of adherence to the colonization of the gastric niche has been highlighted by several studies showing a positive correlation between BabA-mediated adherence to $\mathrm{Le}^{\mathrm{b}}$ antigens and an increased bacterial colonization. Indeed, patients with gastric $\mathrm{Le}^{\mathrm{b}}$ expression had a higher bacterial density than those without $\mathrm{Le}^{\mathrm{b}}$ expression $[118,119]$.

Even so, as explained previously, H. pylori adherence is not solely mediated by BabA-Le ${ }^{\mathrm{b}}$ interaction, as it can also be mediated by Lewis antigens other than $\mathrm{Le}^{\mathrm{b}}$, such as $\mathrm{Le}^{\mathrm{a}}$, $\mathrm{Le}^{\mathrm{x}}$ and its sialylated form, most likely via other adhesins [119]. Added proof is the fact that H. pylori can establish a chronic infection in both weak-secretor and non-secretor individuals as well, with these phenotypes estimated to affect nearly $20 \%$ of the human population $[57,120,121]$. In line with this, a study showed that BabA and SabA-negative strains could bind to gastric tissue in an AlpAB-dependent manner [22].

Several studies showed that adherence of $H$. pylori to the gastric mucosa plays a pivotal role in the outcome of infection. Indeed, the attachment of the bacterium to the epithelial cells induces signal transduction pathways in gastric cells, with activation of the transcription factor nuclear factor- $\mathrm{\kappa B}$. Subsequently, the cytokine IL-8 (an important T cell and neutrophil chemoattractant, and critical mediator in the H. pylori induced inflammatory process) is produced. One mode is through BabA-mediated binding to the host cells, which enables translocation of CagA, triggering a strong cytokine response. 
Moreover, once translocated, CagA activates numerous host signaling pathways, inducing epithelial responses with carcinogenic potential, for a review see $[122,123]$ and references cited therein (Figure 3).

Figure 3. The role of bacterial adherence in Helicobacter pylori virulence.

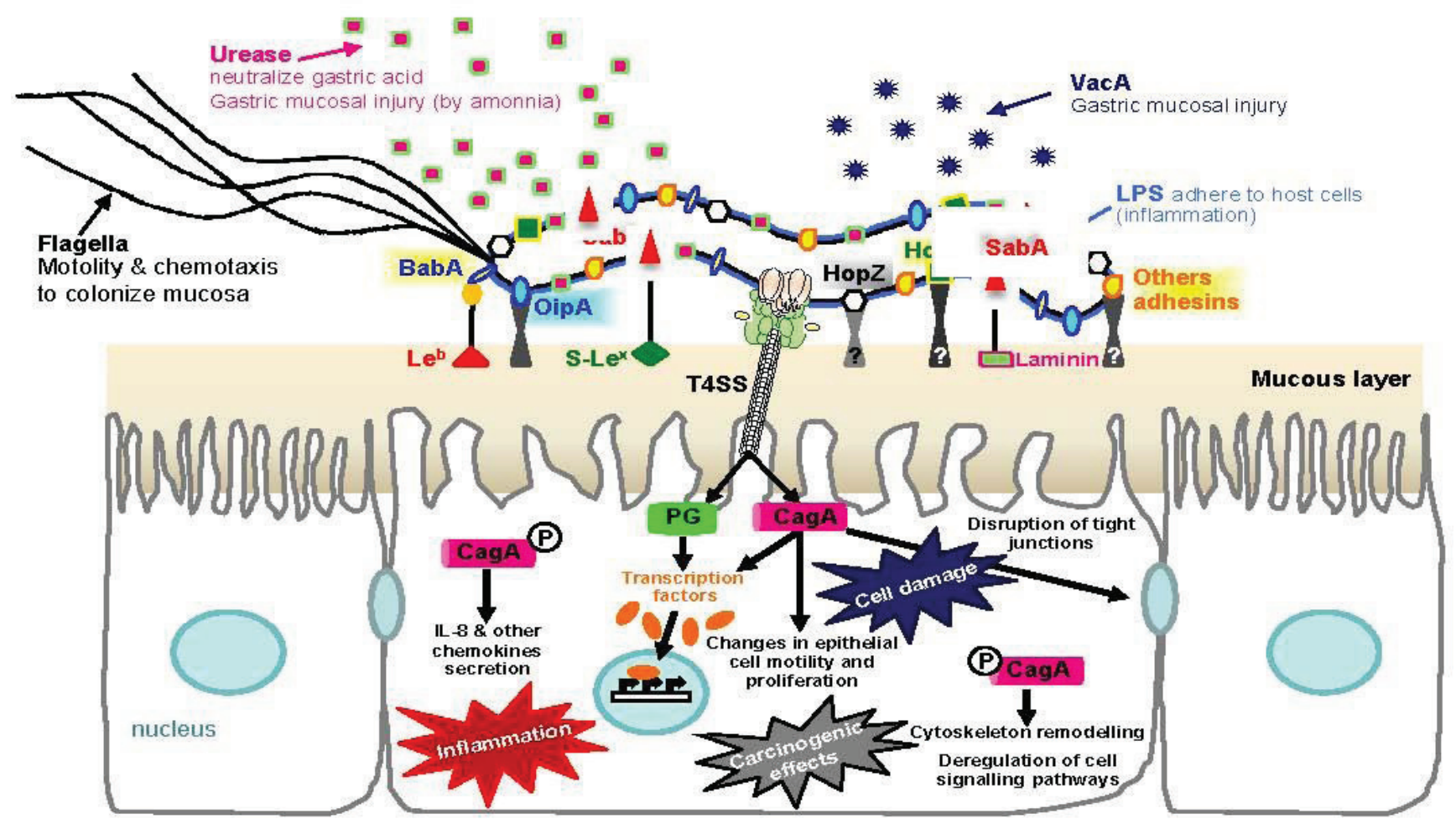

In the mucous layer, H. pylori binds to the apical membrane of gastric epithelial cells via BabA, SabA and other adhesins. The role H. pylori LPS in adherence to gastric epithelial cells is still unclear [19-22]. H. pylori strains expressing a type IV secretion system (T4SS) encoded by the cag pathogenicity island are known to upregulate transcription factors such as the nuclear factor (NF)- $\mathrm{B}$, leading to production of pro-inflammatory cytokines and chemokines. Once adherent, H. pylori assembles T4SS pili (a needle-like pilus device) at their surface enabling the translocation of bacterial effector proteins into the cytoplasm of host gastric epithelial cells, such as the CagA oncoprotein and peptidoglycan. The intracellular delivery of CagA activates numerous host signaling pathways, inducing epithelial responses with carcinogenic potential. $\mathrm{Le}^{\mathrm{b}}$, fucosylated Lewis $\mathrm{b}$ blood group antigen; S-Le ${ }^{\mathrm{x}}$, sialyl-dimeric-Lewis $\mathrm{x}$ glycosphingolipid; LPS, lipopolysaccharide; P, phosphorylated; PG, peptidoglycan.

The biological importance of the adhesin $\mathrm{BabA}-\mathrm{Le}^{\mathrm{b}}$ receptor interaction on the pathogenic features of $H$. pylori has been highlighted in several studies [56,124]. Recently, it was shown both in vitro and in vivo that BabA-mediated binding of $H$. pylori to $\mathrm{Le}^{\mathrm{b}}$ on the epithelial surface increases T4SS-dependent $H$. pylori pathogenicity by triggering the production of proinflammatory cytokines CCL5 and IL-8 and the precancer-related factors, CDX2 and MUC2 [54].

The role of $H$. pylori attachment in the determination of clinical outcome has also been demonstrated by the epidemiological link between adherence-encoding genes and virulence determinants. In Western countries, clinical strains harbouring the triple genotype babA, cagA and the most virulent allele of $v a c \mathrm{~A}$, the s1 allele, have been associated with duodenal ulcer and gastric adenocarcinoma [58,124,125]. The correlation of $H$. pylori adherence with inflammation and more severe disease outcome was also demonstrated for another less well studied OMP, HomB [102-104]. 
In vitro co-culture assays on gastric epithelial AGS cells revealed that HomB contributes to bacterial adherence and induces activation of IL-8 secretion, depending on the number of hom $\mathrm{B}$ copies present in a strain (Figure 2) [29].

A recent study explored how $H$. pylori is affected by the host, in particular by the host mucins, and what impact this regulation may have on the clinical outcome. The authors showed that mucin binding ability via BabA was an important factor for enhancing the $H$. pylori proliferation, with higher proliferation rates being observed with tumor-derived mucins and mucins from the surface mucosa, consisting mostly of MUC5AC, than with gland-derived mucins consisting mainly of MUC6 [126]. In addition, they showed that, in an adherence dependent manner, H. pylori responded to the presence of mucins with an upregulation of genes involved in colonization (babA, sabA, flaA and ureA) and virulence processes (cagA), suggesting once again that these genes are co-regulated in response to mucins. Therefore, the authors hypothesized that regulation of $H$. pylori by mucins may be an important explanation for individual variations in host response and symptoms following infection [126].

Besides the interaction of BabA adhesin and structural T4SS proteins in causing gastric lesions through CagA injection, it was shown, using the mouse model of infection, that the attachment of H. pylori to $\mathrm{Le}^{\mathrm{b}}$ led to an increase in the production of auto-antibodies to the host $\mathrm{Le}^{\mathrm{x}}$ antigens, produced either in bacterial LPS and in the acid-secreting parietal cells [127]. These data also suggests a significant impact of $H$. pylori adherence on the development of gastritis and gastric atrophy.

\section{Conclusions}

The gastric pathogen $H$. pylori has colonized the human stomach for more than two hundred thousand years and, despite a currently declining infection in developed western countries, it continues to spread among humans, with high incidence in developing countries in Asia and Africa. This unequivocal success as a pathogen/colonizer is due to complex strategies to maintain an inflammation of the gastric epithelium while limiting the extent of the immune response in order to prevent its elimination. One of the mechanisms contributing to an active host adaptation is without a doubt its adherence to the mucus layer and to the gastric epithelial cells, a complex phenotype involving multiple adhesins and different receptors whose availability changes according to inflammation and glycan expression at the epithelial surface. These molecules are all part of the vast repertoire of OMPs displayed by $H$. pylori strains, which are subjected to different mechanisms that alter and regulate their expression, therefore playing a role in the colonization of the bacteria, persistence of infection and ultimately in the severity of the associated disease. H. pylori adherence is far from being clear and future work should be carried out in search of additional adhesins as well as in clarifying the complex adherence-receptor network. Ultimately, these data should provide novel bacterial therapeutic or vaccine targets for the eradication of this persistent bacterium.

\section{Acknowledgments}

The authors wish to thank Jonathan Ferrand (INSERM U853 University Bordeaux Segalen, Bordeaux, France) for supplying the images presented in Figure $2 \mathrm{~B}$ of this review. The work regarding HomB protein was supported in part by the "Institut national de la santé et de la recherche médicale" (INSERM), the University Bordeaux Segalen, the Conseil Régional d'Aquitaine (Bordeaux, France), 
the Fundaçào para a Ciência e Tecnologia (project PPCDT/SAL-IMI/57297/2004) (Portugal), the Sociedade Portuguesa de Gastrenterologia and the Programme de Cooperation Scientifique et Technique Franco-Portugais, sponsored by the French Embassy in Portugal, for supporting the project.

\section{Conflicts of Interest}

The authors declare no conflict of interest.

\section{References}

1. Marshall, B.J.; Warren, J.R. Unidentified curved bacilli in the stomach of patients with gastritis and peptic ulceration. Lancet 1984, 1, 1311-1315.

2. Falush, D.; Wirth, T.; Linz, B.; Pritchard, J.K.; Stephens, M.; Kidd, M.; Blaser, M.J.; Graham, D.Y.; Vacher, S.; Perez-Perez, G.I.; et al. Traces of human migrations in Helicobacter pylori populations. Science 2003, 299, 1582-1585.

3. IARC Working Group on the Evaluation of Carcinogenic Risks to Humans. Schistosomes, liver flukes and Helicobacter pylori. In Monographs on the Evaluation of Carcinogenic Risks to Humans; World Health Organization, International Agency for Research on Cancer: Lyon, France, 1994; Volume 61; pp. 1-241.

4. González, C.; Megraud, F.; Buissonniere, A.; Lujan Barroso, L.; Agudo, A.; Duell, E.J.; Boutron-Ruault, M.C.; Clavel-Chapelon, F.; Palli, D.; Krogh, V.; et al. Helicobacter pylori infection assessed by ELISA and by immunoblot and noncardia gastric cancer risk in a prospective study: The Eurgast-EPIC project. Ann. Oncol. 2012, 23, 1320-1324.

5. Banic, M.; Franceschi, F.; Babic, Z.; Gasbarrini, A. Extragastric manifestations of Helicobacter pylori infection. Helicobacter 2012, 17, 49-55.

6. Fukase, K.; Kato, M.; Kikuchi, S.; Inoue, K.; Uemura, N.; Okamoto, S.; Terao, S.; Amagai, K.; Hayashi, S.; Asaka, M.; The Japan Gast Study Group. Effect of eradication of Helicobacter pylori on incidence of metachronous gastric carcinoma after endoscopic resection of early gastric cancer: An open-label, randomised controlled trial. Lancet 2008, 372, 392-397.

7. Malfertheiner, P.; Megraud, F.; O’Morain, C.; Bazzoli, F.; El-Omar, E.; Graham, D.; Hunt, R.; Rokkas, T.; Vakil, N.; Kuipers, E.J.; et al. Current concepts in the management of Helicobacter pylori infection: The Maastricht III Consensus Report. Gut 2007, 56, 772-781.

8. Backert, S.; Clyne, M.; Tegtmeyer, N. Molecular mechanisms of gastric epithelial cell adhesion and injection of CagA by Helicobacter pylori. Cell Commun. Signal 2011, 9, 28.

9. Suerbaum, S.; Achtman, M. Evolution of Helicobacter pylori: The role of recombination. Trends Microbiol. 1999, 7, 182-184.

10. Falush, D.; Kraft, C.; Taylor, N.S.; Correa, P.; Fox, J.G.; Achtman, M.; Suerbaum, S. Recombination and mutation during long-term gastric colonization by Helicobacter pylori: Estimates of clock rates, recombination size, and minimal age. Proc. Natl. Acad. Sci. USA 2001, 98, 15056-15061.

11. Odenbreit, S.; Swoboda, K.; Barwig, I.; Ruhl, S.; Borén, T.; Koletzko, S.; Haas, R. Outer membrane protein expression profile in Helicobacter pylori clinical isolates. Infect. Immun. 2009, 77, 3782-3790. 
12. Suerbaum, S.; Josenhans, C. Helicobacter pylori evolution and phenotypic diversification in a changing host. Nat. Rev. Microbiol. 2007, 5, 441-452.

13. Morelli, G.; Didelot, X.; Kusecek, B.; Schwarz, S.; Bahlawane, C.; Falush, D.; Suerbaum, S.; Achtman, M. Microevolution of Helicobacter pylori during prolonged infection of single hosts and within families. PLoS Genet. 2010, 6, e1001036.

14. Kuipers, E.J.; Israel, D.A.; Kusters, J.G.; Gerrits, M.M.; Weel, J.; van der Ende, A.; van der Hulst, R.; Wirth, H.P.; Höök-Nikanne, J.; Thompson, S.A.; et al. Quasispecies development of Helicobacter pylori observed in paired isolates obtained years apart from the same host. J. Infect. Dis. 2000, 181, 273-282.

15. Muotiala, A.; Helander, I.M.; Pyhala, L.; Kosunen, T.U.; Moran, A.P. Low biological activity of Helicobacter pylori lipopolysaccharide. Infect. Immun. 1992, 60, 1714-1716.

16. Monteiro, M.A.; Appelmelk, B.J.; Rasko, D.A.; Moran, A.P.; Hynes, S.O.; MacLean, L.L.; Chan, K.H.; Michael, F.S.; Logan, S.M.; O’Rourke, J.; et al. Lipopolysaccharide structures of Helicobacter pylori genomic strains 26695 and J99, mouse model H-pylori Sydney strain, H-pylori P466 carrying sialyl Lewis X, and H-pylori UA915 expressing Lewis B-Classification of H-pylori lipopolysaccharides into glycotype families. Eur. J. Biochem. 2000, 267, 305-320.

17. Appelmelk, B.J.; Shiberu, B.; Trinks, C.; Tapsi, N.; Zheng, P.Y.; Verboom, T.; Maaskant, J.; Hokke, C.H.; Schiphorst, W.E.; Blanchard, D.; et al. Phase variation in Helicobacter pylori lipopolysaccharide. Infect. Immun. 1998, 66, 70-76.

18. Edwards, N.J.; Monteiro, M.A.; Faller, G.; Walsh, E.J.; Moran, A.P.; Roberts, I.S.; High, N.J. Lewis $\mathrm{X}$ structures in the $\mathrm{O}$ antigen side-chain promote adhesion of Helicobacter pylori to the gastric epithelium. Mol. Microbiol. 2000, 35, 1530-1539.

19. Monteiro, M.A.; Chan, K.H.N.; Rasko, D.A.; Taylor, D.E.; Zheng, P.Y.; Appelmelk, B.J.; Wirth, H.P.; Yang, M.; Blaser, M.J.; Hynes, S.O.; et al. Simultaneous expression of type 1 and type 2 Lewis blood group antigens by Helicobacter pylori lipopolysaccharides. J. Biol. Chem. 1998, 273, 11533-11543.

20. Osaki, T.; Yamaguchi, H.; Taguchi, H.; Fukuda, M.; Kawakami, H.; Hirano, H.; Watanabe, S.; Takagi, A.; Kamiya, S. Establishment and characterisation of a monoclonal antibody to inhibit adhesion of Helicobacter pylori to gastric epithelial cells. J. Med. Microbiol. 1998, 47, 505-512.

21. Fowler, M.; Thomas, R.J.; Atherton, J.; Roberts, I.S.; High, N.J. Galectin-3 binds to Helicobacter pylori O-antigen: It is upregulated and rapidly secreted by gastric epithelial cells in response to H. pylori adhesion. Cell. Microbiol. 2006, 8, 44-54.

22. Odenbreit, S.; Faller, G.; Haas, R. Role of the AlpAB proteins and lipopolysaccharide in adhesion of Helicobacter pylori to human gastric tissue. Int. Med. Microbiol. 2002, 292, 247-256.

23. Mahdavi, J.; Boren, T.; Vandenbroucke Grauls, C.; Appelmelk, B.J. Limited role of lipopolysaccharide lewis antigens in adherence of Helicobacter pylori to the human gastric epithelium. Infect. Immun. 2003, 71, 2876-2880.

24. Alm, R.A.; Bina, J.; Andrews, B.M.; Doig, P.; Hancock, R.E.W.; Trust, T.J. Comparative genomics of Helicobacter pylori: Analysis of the outer membrane protein families. Infect. Immun. 2000, 68, 4155-4168.

25. Doig, P.; Exner, M.M.; Hancock, R.E.W.; Trust, T.J. Isolation and characterization of a conserved porin protein from Helicobacter pylori. J. Bacteriol. 1995, 177, 5447-5452. 
26. Exner, M.M.; Doig, P.; Trust, T.J.; Hancock, R.E. Isolation and characterization of a family of porin proteins from Helicobacter pylori. Infect. Immun. 1995, 63, 1567-1572.

27. Ilver, D.; Arnqvist, A.; Ögren, J.; Frick, I.M.; Kersulyte, D.; Incecik, E.T.; Berg, D.E.; Covacci, A.; Engstrand, L.; Borén, T. Helicobacter pylori adhesin binding fucosylated histo-blood group antigens revealed by retagging. Science 1998, 279, 373-377.

28. Mahdavi, J.; Sonden, B.; Hurtig, M.; Olfat, F.O.; Forsberg, L.; Roche, N.; Ăngström, J.; Larsson, T.; Teneberg, S.; Karlsson, K.A.; et al. Helicobacter pylori SabA adhesin in persistent infection and chronic inflammation. Science 2002, 297, 573-578.

29. Oleastro, M.; Cordeiro, R.; Ferrand, J.; Nunes, B.; Lehours, P.; Carvalho-Oliveira, I.; Mendes, A.L.; Monteiro, L.; Mégraud, F.; Ménard, A. Evaluation of the clinical significance of homB, a novel candidate marker of Helicobacter pylori strains associated with peptic ulcer disease. J. Infect. Dis. 2008, 198, 1379-1387.

30. Yamaoka, Y. Roles of Helicobacter pylori BabA in gastroduodenal pathogenesis. World J. Gastroenterol. 2008, 14, 4265-4272.

31. Moore, M.; Borén, T.; Solnick, J. Life at the margins: Modulation of attachment proteins in Helicobacter pylori. Gut Microbes 2011, 2, 42-46.

32. Borén, T.; Falk, P.; Roth, K.A.; Larson, G.; Normark, S. Attachment of Helicobacter pylori to human gastric epithelium mediated by blood group antigens. Science 1993, 262, 1892-1895.

33. Aspholm-Hurtig, M.; Dailide, G.; Lahmann, M.; Kalia, A.; Ilver, D.; Roche, N.; Vikström, S.; Lindén, S.; Bäckström, A.; Lundberg, C.; et al. Functional adaptation of BabA, the H. pylori ABO blood group antigen binding adhesin. Science 2004, 305, 519-522.

34. Sakamoto, S.; Watanabe, T.; Tokumaru, T.; Takagi, H.; Nakazato, H.; Lloyd, K.O. Expression of Lewis $^{\mathrm{a}}$, Lewis ${ }^{\mathrm{b}}$, Lewis ${ }^{\mathrm{x}}$, Lewis ${ }^{\mathrm{y}}$, siayl-Lewis ${ }^{\mathrm{a}}$, and sialyl-Lewis ${ }^{\mathrm{x}}$ blood group antigens in human gastric carcinoma and in normal gastric tissue. Cancer Res. 1989, 49, 745-752.

35. Benktander, J.; Ångström, J.; Breimer, M.; Teneberg, S. Redefinition of the carbohydrate binding specificity of Helicobacter pylori BabA adhesin. J. Biol. Chem. 2012, 287, 31712-31724.

36. Walz, A.; Odenbreit, S.; Mahdavi, J.; Boren, T.; Ruhl, S. Identification and characterization of binding properties of Helicobacter pylori by glycoconjugate arrays. Glycobiology 2005, 15, 700-708.

37. Walz, A.; Odenbreit, S.; Stühler, K.; Wattenberg, A.; Meyer, H.E.; Mahdavi, J.; Borén, T.; Ruhl, S. Identification of glycoprotein receptors within the human salivary proteome for the lectin-like BabA and SabA adhesins of Helicobacter pylori by fluorescence-based 2-D bacterial overlay. Proteomics 2009, 9, 1582-1592.

38. Tamura, K.; Peterson, D.; Peterson, N.; Stecher, G.; Nei, M.; Kumar, S. MEGA5: Molecular evolutionary genetics analysis using maximum likelihood, evolutionary distance, and maximum parsimony methods. Mol. Biol. Evol. 2011, 28, 2731-2739.

39. Tamura, K.; Nei, M.; Kumar, S. Prospects for inferring very large phylogenies by using the neighbor-joining method. Proc. Natl. Acad. Sci. USA 2004, 101, 11030-11035.

40. Aspholm, M.; Olfat, F.O.; Nordén, J.; Sondén, B.; Lundberg, C.; Sjöström, R.; Altraja, S.; Odenbreit, S.; Haas, R.; Wadström, T.; et al. SabA is the H. pylori hemagglutinin and is polymorphic in binding to sialylated glycans. PLoS Pathog. 2006, 2, el10. 
41. Unemo, M.; Aspholm-Hurtig, M.; Ilver, D.; Bergström, J.; Borén, T.; Danielsson, D.; Teneberg, S. The sialic acid binding SabA adhesin of Helicobacter pylori is essential for nonopsonic activation of human neutrophils. J. Biol. Chem. 2005, 280, 15390-15397.

42. Odenbreit, S.; Till, M.; Hofreuter, D.; Faller, G.; Haas, R. Genetic and functional characterization of the alpAB gene locus essential for the adhesion of Helicobacter pylori to human gastric tissue. Mol. Microbiol. 1999, 31, 1537-1548.

43. Senkovich, O.A.; Yin, J.; Ekshyyan, V.; Conant, C.; Traylor, J.; Adegboyega, P.; McGee, D.J.; Rhoads, R.E.; Slepenkov, S.; Testerman, T.L. Helicobacter pylori AlpA and AlpB bind host laminin and influence gastric inflammation in gerbils. Infect. Immun. 2011, 79, 3106-3116.

44. Pride, D.T.; Blaser, M.J. Concerted evolution between duplicated genetic elements in Helicobacter pylori. J. Mol. Biol. 2002, 316, 629-642.

45. Pride, D.T.; Meinersmann, R.J.; Blaser, M.J. Allelic variation within Helicobacter pylori babA and babB. Infect. Immun. 2001, 69, 1160-1171.

46. Colbeck, J.C.; Hansen, L.M.; Fong, J.M.; Solnick, J.V. Genotypic profile of the outer membrane proteins BabA and BabB in clinical isolates of Helicobacter pylori. Infect. Immun. 2006, 74, 4375-4378.

47. Backstrom, A.; Lundberg, C.; Kersulyte, D.; Berg, D.E.; Boren, T.; Arnqvist, A. Metastability of Helicobacter pylori bab adhesin genes and dynamics in Lewis b antigen binding. Proc. Natl. Acad. Sci. USA 2004, 101, 16923-16928.

48. Solnick, J.V.; Hansen, L.M.; Salama, N.R.; Boonjakuakul, J.K.; Syvanen, M. Modification of Helicobacter pylori outer membrane protein expression during experimental infection of Rhesus macaques. Proc. Natl. Acad. Sci. USA 2004, 101, 2106-2111.

49. Matteo, M.; Armitano, R.; Romeo, M.; Wonaga, A.; Olmos, M.; Catalano, M. Helicobacter pylori bab genes during chronic colonization. Int. J. Mol. Epidemiol. Genet. 2011, 30, 286-291.

50. Styer, C.M.; Hansen, L.M.; Cooke, C.L.; Gundersen, A.M.; Choi, S.S.; Berg, D.E.; Benghezal, M.; Peek, R.M.; Borén, T.; Solnick, J.V.; et al. Expression of the BabA adhesin during experimental infection with Helicobacter pylori. Infect. Immun. 2010, 78, 1593-1600.

51. Ohno, T.; Vallström, A.; Rugge, M.; Ota, H.; Graham, D.Y.; Arnqvist, A.; Yamaoka, Y. Effects of blood group antigen-binding adhesin expression during Helicobacter pylori infection of Mongolian gerbils. J. Infect. Dis. 2011, 203, 726-735.

52. Hennig, E.; Allen, J.; Cover, T. Multiple chromosomal loci for the babA gene in Helicobacter pylori. Infect. Immun. 2006, 74, 3046-3051.

53. Armitano, R.; Matteo, M.; Goldman, C.; Wonaga, A.; Viola, L.A.; de Palma, G.Z.; Catalano, M. Helicobacter pylori heterogeneity in patients with gastritis and peptic ulcer disease. Infect. Genet. Evol. 2013, 16, 377-385.

54. Ishijima, N.; Suzuki, M.; Ashida, H.; Ichikawa, Y.; Kanegae, Y.; Saito, I.; Borén, T.; Haas, R.; Sasakawa, C.; Mimuro, H. BabA-mediated adherence is a potentiator of the Helicobacter pylori type IV secretion system activity. J. Biol. Chem. 2011, 286, 25256-25264.

55. Toller, I.M.; Neelsen, K.J.; Steger, M.; Hartung, M.L.; Hottiger, M.O.; Stucki, M.; Kalali, B.; Gerhard, M.; Sartori, A.A.; Lopes, M.; et al. Carcinogenic bacterial pathogen Helicobacter pylori triggers DNA double-strand breaks and a DNA damage response in its host cells. Proc. Natl. Acad. Sci. USA 2011, 108, 14944-14949. 
56. Fujimoto, S.; Olaniyi, O.O.; Arnqvist, A.; Wu, J.Y.; Odenbreit, S.; Haas, R.; Graham, D.Y.; Yamaoka, Y. Helicobacter pylori BabA expression, gastric mucosal injury, and clinical outcome. Clin. Gastroenterol. Hepatol. 2007, 5, 49-58.

57. Azevedo, M.; Eriksson, S.; Mendes, N.; Serpa, J.; Figueiredo, C.; Resende, L.P.; Ruvoën-Clouet, N.; Haas, R.; Borën, T.; Le Pedun, J.; et al. Infection by Helicobacter pylori expressing the BabA adhesin is influenced by the secretor phenotype. J. Pathol. 2008, 215, 308-316.

58. Gerhard, M.; Lehn, N.; Neumayer, N.; Borén, T.; Rad, R.; Schepp, W.; Miehlke, S.; Classen, M.; Prinz, C. Clinical relevance of the Helicobacter pylori gene for blood-group antigen-binding adhesin. Proc. Natl. Acad. Sci. USA 1999, 96, 12778-12783.

59. Yamaoka, Y. Increasing evidence of the role of Helicobacter pylori SabA in the pathogenesis of gastroduodenal disease. J. Infect. Dev. Ctries. 2008, 2, 174-181.

60. Talarico, S.; Whitefield, S.E.; Fero, J.; Haas, R.; Salama, N.R. Regulation of Helicobacter pylori adherence by gene conversion. Mol. Microbiol. 2012, 84, 1050-1061.

61. Yamaoka, Y.; Kita, M.; Kodama, T.; Imamura, S.; Ohno, T.; Sawai, N.; Ishimaru, A.; Imanishi, J.; Graham, D.Y. Helicobacter pylori infection in mice: Role of outer membrane proteins in colonization and inflammation. Gastroenterology 2002, 123, 1992-2004.

62. Loh, J.T.; Torres, V.J.; Algood, H.M.; McClain, M.S.; Cover, T.L. Helicobacter pylori HopQ outer membrane protein attenuates bacterial adherence to gastric epithelial cells. FEMS Microbiol. Lett. 2008, 289, 53-58.

63. Merrell, D.S.; Goodrich, M.L.; Otto, G.; Tompkins, L.S.; Falkow, S. pH-regulated gene expression of the gastric pathogen Helicobacter pylori. Infect. Immun. 2003, 71, 3529-3539.

64. Yamaoka, Y.; Ojo, O.; Fujimoto, S.; Odenbreit, S.; Haas, R.; Gutierrez, O.; El-Zimaity, H.M.T.; Reddy, R.; Arnqvist, A.; Graham, D.Y. Helicobacter pylori outer membrane proteins and gastroduodenal disease. Gut 2006, 55, 775-781.

65. Saunders, N.J.; Boonmee, P.; Peden, J.F.; Jarvis, S.A. Inter-species horizontal transfer resulting in core-genome and niche-adaptive variation within Helicobacter pylori. BMC Genomics 2005, 6, 9.

66. Kao, C.Y.; Sheu, B.S.; Sheu, S.M.; Yang, H.B.; Chang, W.L.; Cheng, H.C.; Wu, J.J. Higher motility enhances bacterial density and inflammatory response in dyspeptic patients infected with Helicobacter pylori. Helicobacter 2012, 17, 411-416.

67. Sheu, B.; Odenbreit, S.; Hung, K.H.; Liu, C.P.; Sheu, S.M.; Yang, H.B.; Wu, J.J. Interaction between host gastric Sialyl-Lewis $\mathrm{X}$ and H. pylori SabA enhances H. pylori density in patients lacking gastric Lewis B antigen. Am. J. Gastroenterol. 2006, 101, 36-44.

68. Marcos, N.T.; Magalhães, A.; Ferreira, B.; Oliveira, M.J.; Carvalho, A.S.; Mendes, N.; Gilmartin, T.; Head, S.R.; Figueiredo, C.; David, L.; et al. Helicobacter pylori induces beta3GnT5 in human gastric cell lines, modulating expression of the SabA ligand sialyl-Lewis x. J. Clin. Invest. 2008, 118, 2325-2336.

69. Bernarde, C.; Lehours, P.; Lasserre, J.P.; Castroviejo, M.; Mégraud, F.; Ménard, A. Complexomics study of two Helicobacter pylori strains of two pathological origins: Potential targets for vaccine development and new insight in bacteria metabolism. Mol. Cell Proteomics 2010, 9, 2796-2826. 
70. Alm, R.A.; Ling, L.S.L.; Moir, D.T.; King, B.L.; Brown, E.D.; Doig, P.C.; Smith, D.R.; Noonan, B.; Guild, B.C.; deJonge, B.L.; et al. Genomic-sequence comparison of two unrelated isolates of the human gastric pathogen Helicobacter pylori. Nature 1999, 397, 176-180.

71. Baik, S.C.; Kim, K.M.; Song, S.M.; Kim, D.S.; Jun, J.S.; Lee, S.G.; Song, J.Y.; Park, J.U.; Kang, H.L.; Lee, W.K.; et al. Proteomic analysis of the sarcosine-insoluble outer membrane fraction of Helicobacter pylori strain 26695. J. Bacteriol. 2004, 186, 949-955.

72. Odenbreit, S.; Till, M.; Hofreuter, D.; Haas, R. Outer membrane proteins AlpA and AlpB are involved in H. pylori binding to epithelial cells. Gut 1997, 41, A107.

73. De Jonge, R.; Durrani, Z.; Rijpkema, S.G.; Kuipers, E.J.; van Vliet, A.H.; Kusters, J.G. Role of the Helicobacter pylori outer-membrane proteins AlpA and AlpB in colonization of the guinea pig stomach. J. Med. Microbiol. 2004, 53, 375-379.

74. Sugimoto, M.; Ohno, T.; Graham, D.; Yamaoka, Y. Helicobacter pylori outer membrane proteins on gastric mucosal interleukin 6 and 11 expression in Mongolian gerbils. J. Gastroenterol. Hepatol. 2011, 26, 1677-1684.

75. Lu, H.; Wu, J.Y.; Beswick, E.J.; Ohno, T.; Odenbreit, S.; Haas, R.; Reyes, V.E.; Kita, M.; Graham, D.Y.; Yamaoka, Y. Functional and intracellular signaling differences associated with the Helicobacter pylori AlpAB adhesin from Western and East Asian strains. J. Biol. Chem. 2007, 282, 6242-6254.

76. Huang, C.H.; Chiou, S.H. Proteomic analysis of upregulated proteins in Helicobacter pylori under oxidative stress induced by hydrogen peroxide. Kaohsiung J. Med. Sci. 2011, 27, 544-553.

77. Xue, J.; Bai, Y.; Chen, Y.; Wang, J.D.; Zhang, Z.S.; Zhang, Y.L.; Zhou, D.Y. Expression of Helicobacter pylori AlpA protein and its immunogenicity. World J. Gastroenterol. 2005, 11, 2260-2263.

78. Bai, Y.; Zhang, Y.; Wang, J.; Lin, H.; Zhang, Z.; Zhou, D. Conservative region of the genes encoding four adhesins of Helicobacter pylori: Cloning, sequence analysis and biological information analysis. Di Yi Jun Yi Da Xue Xue Bao 2002, 22, 869-871.

79. Sun, Z.L.; Bi ,Y.W.; Bai, C.M.; Gao, D.D.; Li, Z.H.; Dai, Z.X.; Li, J.F.; Xu, W.M. Expression of Helicobacter pylori alpA gene in Lactococcus lactis and its immunogenicity analysis. Xi Bao Yu Fen Zi Mian Yi Xue Za Zhi 2010, 26, 203-206.

80. Yamaoka, Y.; Kwon, D.H.; Graham, D.Y. A M(r) 34,000 proinflammatory outer membrane protein (OipA) of Helicobacter pylori. Proc. Natl. Acad. Sci. USA 2000, 97, 111-133.

81. Yamaoka, Y.; Kikuchi, S.; El-Zimaity, H.M.T.; Gutierrez, O.; Osato, M.S.; Graham, D.Y. Importance of Helicobacter pylori oipA in clinical presentation, gastric inflammation, and mucosal interleukin 8 production. Gastroenterology 2002, 123, 414-424.

82. Tabassam, F.H.; Graham, D.Y.; Yamaoka, Y. Helicobacter pylori-associated regulation of forkhead transcription factors FoxO1/3a in human gastric cells. Helicobacter 2012, 17, 193-202.

83. Dossumbekova, A.; Prinz, C.; Mages, J.; Lang, R.; Kusters, J.G.; van Vliet, A.H.; Reindl, W.; Backert, S.; Saur, D.; Schmid, R.M.; et al. Helicobacter pylori HopH (OipA) and bacterial pathogenicity: Genetic and functional genomic analysis of hopH gene polymorphisms. J. Infect. Dis. 2006, 194, 1346-1355. 
84. Franco, A.T.; Johnston, E.; Krishna, U.; Yamaoka, Y.; Israel, D.A.; Nagy, T.A.; Wroblewski, L.E.; Piazuelo, M.B.; Correa, P.; Peek, R.M., Jr. Regulation of gastric carcinogenesis by Helicobacter pylori virulence factors. Cancer Res. 2008, 68, 379-387.

85. Teymournejad, O.; Mobarez, A.M.; Hassan, Z.M.; Moazzeni, S.M.; Yakhchali, B.; Eskandari, V. In silico prediction of exposure amino acid sequences of outer inflammatory protein A of Helicobacter pylori for surface display on Escherichia coli. Indian J. Hum. Genet. 2012, 18, 83-86.

86. Saunders, N.J.; Peden, J.F.; Hood, D.W.; Moxon, E.R. Simple sequence repeats in the Helicobacter pylori genome. Mol. Microbiol. 1998, 27, 1091-1098.

87. Markovska, R.; Boyanova, L.; Yordanov, D.; Gergova, G.; Mitov, I. Helicobacter pylori oipA genetic diversity and its associations with both disease and cagA, vacA s,m, and i alleles among Bulgarian patients. Diagn. Microbiol. Infect. Dis. 2011, 71, 335-340.

88. Tabassam, F.H.; Graham, D.Y.; Yamaoka, Y. OipA plays a role in Helicobacter pylori-induced focal adhesion kinase activation and cytoskeletal re-organization. Cell. Microbiol. 2008, 10, 1008-1020.

89. Tabassam, F.H.; Graham, D.Y.; Yamaoka, Y. Paxillin is a novel cellular target for converging Helicobacter pylori-induced cellular signaling. Am. J. Physiol. Gastrointest. Liver Physiol. 2011, 301, G601-G611.

90. Chen, J.; Lin, M.; Li, N.; Lin, L.; She, F. Therapeutic vaccination with Salmonella-delivered codon-optimized outer inflammatory protein DNA vaccine enhances protection in Helicobacter pylori infected mice. Vaccine 2012, 30, 5310-5315.

91. Chen, J.; Lin, L.; Li, N.; She, F. Enhancement of Helicobacter pylori outer inflammatory protein DNA vaccine efficacy by co-delivery of interleukin-2 and B subunit heat-labile toxin gene encoded plasmids. Microbiol. Immunol. 2012, 56, 85-92.

92. Peck, B.; Ortkamp, M.; Diehl, K.D.; Hundt, E.; Knapp, B. Conservation, localization and expression of HopZ, a protein involved in adhesion of Helicobacter pylori. Nucl. Acids Res. 1999, 27, 3325-3333.

93. Giannakis, M.; Bäckhed, H.K.; Chen, S.L.; Faith, J.J.; Wu, M.; Guruge, J.L.; Engstrand, L.; Gordon, J.I. Response of gastric epithelial progenitors to Helicobacter pylori isolates obtained from Swedish patients with chronic atrophic gastritis. J. Biol. Chem. 2009, 284, 30383-30394.

94. Kennemann, L.; Didelot, X.; Aebischer, T.; Kuhn, S.; Drescher, B.; Droege, M.; Reinhardt, R.; Correa, P.; Meyer, T.F.; Josenhans, C.; et al. Helicobacter pylori genome evolution during human infection. Proc. Natl. Acad. Sci. USA 2011, 108, 5033-5038.

95. Kennemann, L.; Brenneke, B.; Andres, S.; Engstrand, L.; Meyer, T.F.; Aebischer, T.; Josenhans, C.; Suerbaum, S. In vivo sequence variation in HopZ, a phase-variable outer membrane protein of Helicobacter pylori. Infect. Immun. 2012, 80, 4364-4373.

96. De Jonge, R.; Pot, R.G.J.; Loffeld, R.J.L.F.; van Vliet, A.H.M.; Kuipers, E.J.; Kusters, J.G. The functional status of the Helicobacter pylori sabB adhesin gene as a putative marker for disease outcome. Helicobacter 2004, 9, 158-164.

97. Chiarini, A.; Calà, C.; Bonura, C.; Gullo, A.; Giuliana, G.; Peralta, S.; D’Arpa, F.; Giammanco, A. Prevalence of virulence-associated genotypes of Helicobacter pylori and correlation with severity of gastric pathology in patients from western Sicily, Italy. Eur. J. Clin. Microbiol. Infect. Dis. 2009, 28, 437-446. 
98. Lehours, P.; Ménard, A.; Dupouy, S.; Bergey, B.; Richy, F.; Zerbib, F.; Ruskoné-Fourmestraux, A.; Delchier, J.C.; Mégraud, F. Evaluation of the association of nine Helicobacter pylori virulence factors with strains involved in low-grade gastric mucosa-associated lymphoid tissue lymphoma. Infect. Immun. 2004, 72, 880-888.

99. Oleastro, M.; Cordeiro, R.; Ménard, A.; Yamaoka, Y.; Queiroz, D.; Mégraud, F.; Monteiro, L. Allelic diversity and phylogeny of hom $\mathrm{B}$, a novel co-virulence marker of Helicobacter pylori. BMC Microbiol. 2009, 9, 248.

100. Oleastro, M.; Cordeiro, R.; Ménard, A.; Gomes, J.P. Allelic diversity among Helicobacter pylori outer membrane protein genes hom $\mathrm{B}$ and hom $\mathrm{A}$ generated by recombination. J. Bacteriol. 2010, 192, 3961-3968.

101. Oleastro, M.; Monteiro, L.; Lehours, P.; Mégraud, F.; Ménard, A. Identification of markers for Helicobacter pylori strains isolated from children with peptic ulcer disease by suppressive subtractive hybridization. Infect. Immun. 2006, 74, 4064-4074.

102. Oleastro, M.; Cordeiro, R.; Yamaoka, Y.; Queiroz, D.; Mégraud, F.; Monteiro, L.; Ménard, A. Disease association with two Helicobacter pylori duplicate outer membrane protein genes, homB and homA. Gut Pathog. 2009, doi:10.1186/1757-4749-1-12.

103. Jung, S.W.; Sugimoto, M.; Graham, D.Y.; Yamaoka, Y. homB status of Helicobacter pylori as a novel marker to distinguish gastric cancer from duodenal ulcer. J. Clin. Microbiol. 2009, 47, 3241-3245.

104. Abadi, A.T.B.; Rafiei, A.; Ajami, A.; Hosseini, V.; Taghvaei, T.; Jones, K.R.; Merrell, D.S. Helicobacter pylori hom $\mathrm{B}$, but not cagA, is associated with gastric cancer in Iran. J. Clin. Microbiol. 2011, 49, 3191-3197.

105. Hussein, N.R. A study of Helicobacter pylori outer-membrane proteins (hom) A and B in Iraq and Turkey. J. Infect. Public Health 2011, 4, 135-139.

106. Kang, J.; Jones, K.R.; Jang, S.; Olsen, C.H.; Yoo, Y.J.; Merrell, D.S.; Cha, J.H. The geographic origin of Helicobacter pylori influences the association of the hom $\mathrm{B}$ gene with gastric cancer. J. Clin. Microbiol. 2012, 50, 1082-1085.

107. Tomb, J.F.; White, O.; Kerlavage, A.R.; Clayton, R.A.; Sutton, G.G.; Fleischmann, R.D.; Ketchum, K.A.; Klenk, H.P.; Gill, S.; Dougherty, B.A.; et al. The complete genome sequence of the gastric pathogen Helicobacter pylori. Nature 1997, 388, 539-547.

108. Morris, A.; Nicholson, G.; Zwi, J.; Vanderwee, M. Campylobacter pylori infection in Meckel's diverticula containing gastric mucosa. Gut 1989, 30, 1233-1235.

109. Kestemberg, A.; Mariño, G.; de Lima, E.; Garcia, F.; Carrascal, E.; Arredondo, J.L. Gastric heterotopic mucosa in the rectum with Helicobacter pylori-like organisms: A rare cause of rectal bleeding. Int. J. Colorectal Dis. 1993, 8, 9-12.

110. Genta, R.M.; Gurer, I.E.; Graham, D.Y.; Krishnan, B.; Segura, A.M.; Gutierrez, O.; Kim, J.G.; Burchette, J.L., Jr. Adherence of Helicobacter pylori to areas of incomplete intestinal metaplasia in the gastric mucosa. Gastroenterology 1996, 111, 1206-1211.

111. Lindén, S.; Nordman, H.; Hedenbro, J.; Hurtig, M.; Borén, T.; Carlstedt, I. Strain- and blood group-dependent binding of Helicobacter pylori to human gastric MUC5AC glycoforms. Gastroenterology 2002, 123, 1923-1930. 
112. Van den Brink, G.R.; Tytgat, K.; van der Hulst, R.; van der Loos, C.M.; Einerhand, A.; Buller, H.; Dekker, J. H. pylori colocalises with MUC5AC in the human stomach. Gut 2000, 46, 601-607.

113. Nordman, H.; Davies, J.R.; Lindell, G.; de Bolós, C.; Real, F.; Carlstedt, I. Gastric MUC5AC and MUC6 are large oligomeric mucins that differ in size, glycosylation and tissue distribution. Biochem. J. 2002, 364, 191-200.

114. Kawakubo, M.; Ito, Y.; Okimura, Y.; Kobayashi, M.; Sakura, K.; Kasama, S.; Fukuda, M.N.; Katsuyama, T.; Nakayama, J. Natural antibiotic function of a human gastric mucin against Helicobacter pylori infection. Science 2004, 305, 1003-1006.

115. Van de Bovenkamp, J.H.; Mahdavi, J.; Korteland-Van Male, A.M.; Büller, H.A.; Einerhand, A.W.; Borén, T.; Dekker, J. The MUC5AC glycoprotein is the primary receptor for Helicobacter pylori in the human stomach. Helicobacter 2003, 8, 521-532.

116. Magalhães, A.; Gomes, J.; Ismail, M.N.; Haslam, S.M.; Mendes, N.; Osório, H.; David, L.; Le Pendu, J.; Haas, R.; Dell, A.; et al. Fut2-null mice display an altered glycosylation profile and impaired BabA-mediated Helicobacter pylori adhesion to gastric mucosa. Glycobiology 2009, $19,1525-1536$.

117. Correa, P. Human gastric carcinogenesis: A multistep and multifactorial process-First american cancer society award lecture on cancer epidemiology and prevention. Cancer Res. 1992, 52, 6735-6740.

118. Rad, R.; Gerhard, M.; Lang, R.; Schöniger, M.; Rösch, T.; Schepp, W.; Becker, I.; Wagner, H.; Prinz, C. The Helicobacter pylori blood group antigen-binding adhesin facilitates bacterial colonization and augments a nonspecific immune response. J. Immunol. 2002, 168, 3033-3041.

119. Sheu, B.S.; Sheu, S.M.; Yang, H.B.; Huang, A.H.; Wu, J. Host gastric Lewis expression determines the bacterial density of Helicobacter pylori in babA2 genopositive infection. Gut 2003, 52, 927-932.

120. Marionneau, S.; Cailleau-Thomas, A.; Rocher, J.; Le Moullac-Vaidye, B.; Ruvoën, N.; Clément, M.; Le Pendu, J. ABH and Lewis histo-blood group antigens, a model for the meaning of oligosaccharide diversity in the face of a changing world. Biochimie 2001, 83, 565-573.

121. Lindén, S.; Mahdavi, J.; Semino-Mora, C.; Oslen, C.; Carlstedt, I.; Borén, T.; Dubois, A. Role of ABO secretor status in mucosal innate immunity and H. pylori infection. PLoS Pathog. 2008, 4, e2.

122. Murata-Kamiya, N. Pathophysiological functions of the CagA oncoprotein during infection by Helicobacter pylori. Microbes Infect. 2011, 13, 799-807.

123. Hatakeyama, M. Oncogenic mechanisms of the Helicobacter pylori CagA protein. Nat. Rev. Cancer 2004, 4, 688-694.

124. Zambon, C.F.; Navaglia, F.; Basso, D.; Rugge, M.; Plebani, M. Helicobacter pylori babA2, cagA, and s1 vacA genes work synergistically in causing intestinal metaplasia. J. Clin. Pathol. 2003, 56, 287-291.

125. Olfat, F.O.; Zheng, Q.; Oleastro, M.; Voland, P.; Borén, T.; Karttunen, R.; Engstrand, L.; Rad, R.; Prinz, C.; Gerhard, M. Correlation of the Helicobacter pylori adherence factor BabA with duodenal ulcer disease in four European countries. Fems Immunol. Med. Microbiol. 2005, 44, 151-156.

126. Skoog, E.; Sjöling, Å.; Navabi, N.; Holgersson, J.; Lundin, S.B.; Lindén, S.K. Human gastric mucins differently regulate Helicobacter pylori proliferation, gene expression and interactions with host cells. PLoS One 2012, 7, e36378. 
127. Guruge, J.L.; Falk, P.G.; Lorenz, R.G.; Dans, M.; Wirth, H.P.; Blaser, M.J.; Berg, D.E.; Gordon, J.I. Epithelial attachment alters the outcome of Helicobacter pylori infection. Proc. Natl. Acad. Sci. USA 1998, 95, 3925-3930.

(C) 2013 by the authors; licensee MDPI, Basel, Switzerland. This article is an open access article distributed under the terms and conditions of the Creative Commons Attribution license (http://creativecommons.org/licenses/by/3.0/). 